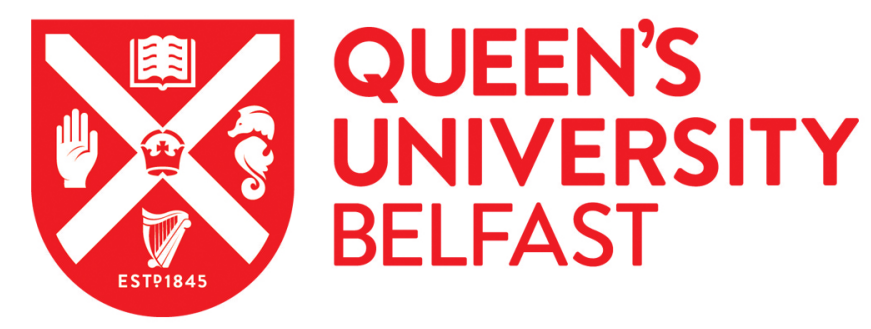

\title{
Critical evaluation of pulse-echo ultrasonic test method for the determination of setting and mechanical properties of acrylic bone cement: Influence of mixing technique
}

Hagan, C. P., Orr, J. F., Mitchell, C. A., \& Dunne, N. J. (2015). Critical evaluation of pulse-echo ultrasonic test method for the determination of setting and mechanical properties of acrylic bone cement: Influence of mixing technique. Ultrasonics, 56, 279-286. https://doi.org/10.1016/j.ultras.2014.08.008

Published in:

Ultrasonics

Document Version:

Peer reviewed version

Queen's University Belfast - Research Portal:

Link to publication record in Queen's University Belfast Research Portal

\section{Publisher rights}

Copyright () 2014 Elsevier B.V.

This manuscript version is made available under the CC-BY-NC-ND 4.0 license http://creativecommons.org/licenses/by-nc-nd/4.0/), which permits distribution and reproduction for non-commercial purposes, provided the author and source are cited.

\section{General rights}

Copyright for the publications made accessible via the Queen's University Belfast Research Portal is retained by the author(s) and / or other copyright owners and it is a condition of accessing these publications that users recognise and abide by the legal requirements associated with these rights.

Take down policy

The Research Portal is Queen's institutional repository that provides access to Queen's research output. Every effort has been made to ensure that content in the Research Portal does not infringe any person's rights, or applicable UK laws. If you discover content in the

Research Portal that you believe breaches copyright or violates any law, please contact openaccess@qub.ac.uk. 
Critical Evaluation of Pulse-Echo Ultrasonic Test Method for the Determination of Setting and Mechanical Properties of Acrylic Bone Cement: Influence of Mixing Technique

Christopher P. Hagan ${ }^{a}$, John F. Orr ${ }^{a}$, Christina A. Mitchell ${ }^{b}$ and Nicholas J. Dunne ${ }^{\text {a* }}$

a School of Mechanical and Aerospace Engineering, Queen’s University Belfast, Belfast, Stranmillis Road, Belfast, BT9 5AH, UK.

b School of Medicine, Dentistry and Biomedical Sciences, Queen’s University Belfast, Grosvenor Road, Belfast, BT12 6BP, UK.

*Corresponding Author: Dr Nicholas Dunne

Email: $\quad$ n.dunne@qub.ac.uk

Telephone: +44 (0) 2890974122

Fax: $\quad$ +44(0) 2890971144 


\begin{abstract}
Currently there is no reliable objective method to quantify the setting properties of acrylic bone cements within an operating theatre environment. Ultrasonic technology can be used to determine the acoustic properties of the polymerising bone cement, which are linked to material properties and provide indications of the physical and chemical changes occurring within the cement. The focus of this study was the critical evaluation of pulse-echo ultrasonic test method in determining the setting and mechanical properties of three different acrylic bone cement when prepared under atmospheric and vacuum mixing conditions. Results indicated that the ultrasonic pulse-echo technique provided a highly reproducible and accurate method of monitoring the polymerisation reaction and indicating the principal setting parameters when compared to ISO 5833 standard, irrespective of the acrylic bone cement or mixing method used. However, applying the same test method to predict the final mechanical properties of acrylic bone cement did not prove a wholly accurate approach. Inhomogeneities within the cement microstructure and specimen geometry were found to have a significant influence on mechanical property predictions. Consideration of all the results suggests that the non-invasive and non-destructive pulse-echo ultrasonic test method is an effective and reliable method for following the full polymerisation reaction of acrylic bone cement in real-time and then determining the setting properties within a surgical theatre environment. However the application of similar technology for predicting the final mechanical properties of acrylic bone cement on a consistent basis may prove difficult.
\end{abstract}

\title{
Keywords
}

Acrylic bone cement, pulse-echo, ultrasound, setting properties, mechanical properties 


\section{Introduction}

Acrylic bone cements are two part systems: (1) the powder comprising of mainly polymethyl methacrylate (PMMA) beads and (2) the liquid component that has methyl methacrylate (MMA) monomer as the principal constituent. During the free radical polymerisation, the viscosity of the cement dough is continually changing, which results in variations in its handling characteristics [1]. The cement mass goes through four phases as polymerisation progresses; (1) mixing, (2) waiting, (3) working and (4) setting phases. At the end of the setting phase the cement is fully hardened, the setting time can be determined during this phase [2].

The duration of each phase is strongly affected by ambient temperature with a $1^{\circ} \mathrm{C}$ increase resulting in a reduction in the overall setting time of approximately $1 \mathrm{~min}[3,4]$. Determination of the stage of cement polymerisation and subsequently whether it is ready for delivery to the bone cavity is determined by the orthopaedic surgeon using physical examination. To assist the orthopaedic surgeon, each cement manufacturer includes technical information with the acrylic cement providing approximate times for each polymerisation phase as a function of ambient temperature. However, other factors also have an effect on the polymerisation reaction of acrylic bone cement. These include cement composition (i.e. different cement brands); powder to liquid ratio [1, 5-7]; cement quantity being mixed [5, 8]; humidity of mixing environment [6, 9]; storage conditions of cement [3, 4, 8, 10]; mixing system used [11] and whether vacuum is applied during mixing $[1,10,12,13]$.

The orthopaedic surgeon is largely interested in the dough time of the cement, which is defined as the time when the cement will first separate cleanly from a gloved finger. Although this seems straightforward, it is a subjective process and can be influenced by other factors. He et al. 
[14] found that indication of the dough time and therefore in start of the working phase can vary by up to $250 \%$ depending on the choice of surgical glove used. Dunne et al. [15] highlighted the uncertainty and subjective nature of this process, which requires a high level of expertise on the part of the orthopaedic surgeon.

Currently, there are no objective techniques available for use in surgical theatres to assist the orthopaedic surgeon in determining the stage of polymerisation of the bone cement. ISO 5833:2002 includes a method for monitoring the temperature of the cement throughout polymerisation. From this, a setting time can be determined, but this is of little value in the clinical environment as it does not provide any real time information on the polymerisation reaction [16]. Successful real-time monitoring of the polymerisation reaction has been achieved using Raman Spectroscopy $[16,17]$ and the results were found to correlate with data generated as per ISO 5833:2002 protocol [2]. Briscoe and New (2010) developed and validated a chemical kinetics model to predict the degree of polymerisation for PMMA bone cement and a second linear computational model to predict mechanical properties and density, which was used to predict residual stresses generation and shrinkage with cement mantles over time [18].

Ultrasonic technology (UT) has been-used successfully to monitor the setting process of calcium sulphate cements $[19,20]$ and there has been some work investigating the use of UT as a characterisation tool for the polymerisation reaction of acrylic bone cements modified with hydroxyapatite [20] and commercially available acrylic bone cements [15]. These studies monitored changes in acoustic properties of the cement during polymerisation and attempted to define a cure time as this would allow direct comparison between different cements. Viano et al. [20] chose the time taken to reach $95 \%$ of the final speed of sound (c) through the fully polymerised cement as the cure time. Dunne et al. [15] used the time at $75 \%$ of the final value of 
c, which correlated with the setting time, determined in accordance with ISO 5833:2002 [2]. A potential correlation between the final acoustic properties of bone cement and the cement's mechanical properties has been reported [15], which would not normally be available to the orthopaedic surgeon.

The aim of this study was to critically evaluate the objectivity and reproducibility of an ultrasonic test method for determining the setting characteristics and mechanical properties of different acrylic bone cements when mixed using the same proprietary mixing and delivery device under atmospheric and vacuum conditions.

\section{Materials and Methods}

\subsection{Cement Preparation}

Three commercially available acrylic bone cements were analysed in this study: Palacos ${ }^{\circledR} \mathrm{R}$ (Heraeus Kulzer, Germany), SmartSet ${ }^{\circledR}$ HV (CMW Laboratories Ltd., UK) and Simplex ${ }^{\circledR}$ P (Stryker Howmedica Osteonics, Ireland). Each batch contained a single mix of cement consisting of $40 \mathrm{~g}$ powder and $20 \mathrm{~mL}$ liquid. All materials and mixing devices were stored at ambient laboratory conditions $\left(22 \pm 1^{\circ} \mathrm{C}, 50 \pm 2 \%\right.$ relative humidity) for a minimum of $24 \mathrm{~h}$ prior to mixing. All cement constituents were mixed using a Summit HiVac ${ }^{\mathrm{TM}}$ Syringe mixing and delivery system (Summit Medical Ltd, UK). Two mixing regimes were adopted: (1) mixing under atmospheric conditions for 30s (60s for Simplex ${ }^{\circledR}$ P) and (2) mixing under a vacuum of $72 \mathrm{kPa}$ for the same duration. After mixing the dough was quickly transferred to the appropriate moulds for monitoring. 


\subsection{Monitoring using Ultrasonic Technology}

In order to determine $c$ through the polymerising cement, a pulse-echo ultrasonic set-up was used. This required only one 10mm diameter transducer (Krautkramer MK1S $1 \mathrm{MHz}$ ) that was used to both transmit and receive ultrasonic pulses. The transducer was attached to a Krautkramer USN60 flaw detector (Agfa NDT Ltd, UK) set to operate in pulse echo mode. This flaw detector has a built in oscilloscope that displayed both transmitted pulses and any echoes received.

After the cement was mixed, $20 \pm 1 \mathrm{~g}$ was transferred into the ultrasonic receptacle (Fig. 1), upon which monitoring began. The transducer surface was coupled with the outer surface of the PMMA buffer [Perspex®); Plastico, Inc., Memphis, TN, USA (density $=1190 \mathrm{kgm}^{-3}$, molecular weight $=227,000 \mathrm{gmol}^{-1}$; glass transition temperature, $100^{\circ} \mathrm{C}$ )], through a thin layer of vacuum grease to ensure complete contact across the surface of the transducer. The surfaces of the transducer, PMMA buffer and mild steel reflector were all parallel to ensure that-any echoes arising from the ultrasonic pulse encountering an interface between two different materials were reflected directly back to the transducer. As the polymerising cement is of primary interest, it was necessary to identify the echoes that corresponded to the buffer/cement interface and the cement/mild steel interface (Fig. 1). The flaw detector allowed manual positioning of cursors over these echoes and the time of flight $(t)$ through the cement could be determined. With the thickness of cement (d) known, it was then possible to calculate the velocity of sound through the cement using Eq. (1).

$$
c=\frac{2 d}{t}
$$

Monitoring began as soon as a signal was established and $t$ was recorded as follows: (1) Every 
15s until 20min was reached; (2) Every 30s from 20-25min; (3) Every 1min from 25-30min; (4) Every 2.5min from 30-45min and (5) Every 5min from 45-60min;

This allowed $c$ to be calculated for each time point, and a graph of $c$ versts. time elapsed to be plotted for the polymerisation reaction. The frequency of the readings was higher during the earlier stages of polymerisation since previous work [16] indicated more rapid polymerisation taking place during the initial 20min. Final measurements of $c$ were repeated $24 \mathrm{~h}$ postpolymerisation. Five tests were conducted for each cement type, prepared under both atmospheric and vacuum conditions. The mean and standard deviation values were subsequently determined for each parameter.

\subsection{Temperature Monitoring}

The maximum temperature and setting time ( $\mathrm{T}_{\max }$ and $\left.\mathrm{t}_{\text {set }}\right)$ were determined in accordance with ISO 5833:2002 [2]. A nickel-chromium-aluminium k-type thermocouple was used along with PicoLog Data Acquisition Software (Pico Technology Ltd., UK). The test equipment was stored in ambient laboratory conditions $\left(22 \pm 3^{\circ} \mathrm{C}, 50 \pm 2 \%\right.$ relative humidity) for a minimum of $2 \mathrm{~h}$, prior

to testing. The temperature was recorded at $1 \mathrm{~s}$ intervals for a period of $1 \mathrm{~h}$, resulting in a temperature trace (Fig 2). As with ultrasonic monitoring, five tests were conducted for each cement type, mixed both under atmospheric and vacuum conditions. Setting times and times at maximum temperature were calculated, mean and standard deviation values were subsequently determined.

\subsection{Preparation of Specimens and Determination of Mechanical Properties}

The ultrasonic monitoring of cement resulted in a block of cement measuring $20 \pm 1 \mathrm{~mm} x$ $20 \pm 1 \mathrm{~mm} \times 30 \pm 1 \mathrm{~mm}$. After the cement had been allowed to cure for a minimum of $24 \mathrm{~h}$ and the 
final $c$ reading had been recorded, the block was machined to create four compressive specimens in accordance with ISO 5833:2002; cylinders of $6 \pm 0.1 \mathrm{~mm}$ diameter and $12 \pm 0.1 \mathrm{~mm}$ in length [2]. The amount of cement required for ultrasonic monitoring was approximately half a single mix of bone cement. The remaining cement was injected into a PTFE mould to form four-point bend specimens of dimensions $3.3 \pm 0.1 \mathrm{~mm} \times 10 \pm 0.1 \mathrm{~mm} \times 75 \pm 0.1 \mathrm{~mm}$, in accordance with ISO 5833:2002 [2].

Mechanical testing was conducted in accordance with ISO 5833:2002 using a Lloyd materials testing machine (Lloyd Instruments Ltd, UK). The bend specimens were loaded at a rate of $5 \mathrm{~mm} / \mathrm{min}$ in four-point bending until failure occurred; a load vs. deformation plot was obtained; the bend strength and bend modulus was calculated. The compressive specimens were loaded under compression at a rate of $20 \mathrm{~mm} / \mathrm{min}$ until a deflection of $3 \mathrm{~mm}$ was achieved; a load vs. deformation plot was obtained from which the compressive strength was then calculated. A minimum of 15 four-point bend specimens and 20 compressive specimens were tested for each bone cement type and mixing condition. The mean and standard deviation were then calculated. After mechanical testing, the value of $c$ through each specimen was determined at the point of fracture using the pulse-echo method.

The density of each specimen was determined using Archimedes' principle. This required each specimen to be weighed in air and in water. The density of the specimen, $\rho$, could then be calculated using Eq. (2):

$$
\rho=\frac{m_{\text {air }} \rho_{\text {water }}}{m_{\text {air }}-m_{\text {water }}}
$$

Where $m_{\text {air }}=$ mass of specimen in air $(\mathrm{kg}) ; m_{\text {water }}=$ mass of specimen when submerged in water $(\mathrm{kg}) ; \rho_{\text {water }}=$ density of water in which specimen was weighed $\left(\mathrm{kgm}^{-3}\right)$. 
A relationship exists between $c$ through a material and the modulus and density of the material Eq. (3) [20].

$c=\sqrt{\frac{E_{Y}}{\rho}}$

Since the bend modulus and density were known for the four-point bend specimens, the theoretical value of $c$ for each specimen was calculated using Eq. (3), for comparison to the experimentally determined value of $c$.

\subsection{Statistical Analysis}

All experimental data was evaluated for statistical differences between atmospheric and vacuum mixing of the acrylic bone cement. If the assumptions for Normality were satisfied, a two sample t-test was used. For non-parametric data a Kruskal-Wallis test was conducted. For both tests a p-value $<0.05$ denoted significance. Correlation analysis was conducted between the final $c$ value and the resultant mechanical properties. For correlation analysis, if the data sets were distributed normally, the Pearson correlation coefficient, $r$, was calculated. If the data was not distributed normally, Spearman's rank correlation coefficient, $r_{s}$, was calculated. If the calculated coefficient was greater than the critical coefficient for that sample size, the relationship was significant at $\mathrm{p}$-value $<0.05$.

\section{Results}

The values of $c$ throughout the polymerisation reactions for SmartSet ${ }^{\circledR}$ HV bone cement mixed under atmospheric and vacuum conditions are shown in Fig. 3. Similar trends were observed for Palacos ${ }^{\circledR}$ R and Simplex ${ }^{\circledR}$ P cements, irrespective of the method of cement mixing. The $c$ vs. time elapsed from start of mixing traces showed an initial plateau, followed by a large sharp rise in $c$, and then another plateau continuing until monitoring was completed. 
Monitoring began after a signal was established, typically $2 \mathrm{~min}$ from the start of cement mixing. Initially, the values of $c$ recorded were between $1400-1500 \mathrm{~ms}^{-1}$. As the cement progressed through the waiting and working phases, there was a slight reduction in $c$ of approximately 15$20 \mathrm{~ms}^{-1}$ for the atmospheric mixed cement and $50-70 \mathrm{~ms}^{-1}$ for cement mixed under a vacuum. As the cement entered the setting phase, there was a rapid rise in $c$. After the initial rapid rise, $c$ continued to rise at a decreasing rate towards its value at $60 \mathrm{~min}$. A further measurement was taken 24h post-polymerisation and for all cements it was found there was negligible change in $c$ during this final period. Vacuum mixing resulted in a higher final $c$ when compared to preparing the cement prepared under atmospheric conditions. The values increased significantly for Palacos ${ }^{\circledR}$ R ( -values $\left.<0.001\right)$ and SmartSet HV (p-values $\left.<0.01\right)$ bone cements. No significant difference in the final $c$ value ( $\mathrm{p}$-value $=0.420$ ) was observed for Simplex ${ }^{\circledR} \mathrm{P}$ bone cement.

Table 1 includes the average times taken to reach $75 \%$ and $95 \%$ of final value of $c$, and the cure duration, which is was defined as the time difference between $75 \%$ and $95 \%$ of final value of $c$. The setting parameters determined using ISO 5833:2002 are also included in Table 1. Both monitoring methods recorded comparable setting properties for all bone cements tested, irrespective of the mixing methods used. Mixing the bone cement under vacuum shortened the setting time for all bone cements tested. The cure duration was not significantly affected by vacuum mixing for Palacos ${ }^{\circledR} \mathrm{R}$ (p-value=0.753), SmartSet ${ }^{\circledR} \mathrm{HV}$ (p-values=0.352) and Simplex ${ }^{\circledR} \mathrm{P}(\mathrm{p}$-values=0.106) bone cements.

When the cement reached a state of full polymerisation, it was possible to investigate the relationship between the acoustic and mechanical properties of the cement (Table 2 and Table 3). For the Palacos ${ }^{\circledR} \mathrm{R}$ and SmartSet ${ }^{\circledR}$ HV bone cement, mixing under vacuum conditions 
improved ( $\mathrm{p}$-values $<0.001$ ) the compressive strength, bend strength, bend modulus and density significantly. For the Simplex ${ }^{\circledR}$ P bone cement, significant improvements were observed in compressive strength ( $\mathrm{p}$-value $<0.001)$, bend modulus $(\mathrm{p}$-value $<0.01)$ and density (pvalue $<0.001$ ), but not bend strength ( $\mathrm{p}$-value $=0.052$ ) under vacuum mixing conditions.

No significant correlation was found between $c$ and compressive strength $\left(r<r_{c r i t}\right.$ or $r_{s}<r_{s}$ crit for all bone cements and mixing conditions investigated. For this sample size, $r_{\text {crit }}=0.878, r_{\mathrm{s} \text { crit }}=$ 0.900) (Table 4). For both Palacos ${ }^{\circledR}$ R and SmartSet ${ }^{\circledR}$ HV bone cements however, the noted increases in density and compressive strength caused by vacuum mixing coincided with the increased values of $c$ found for vacuum mixed bone cement.

As with the associated relationships for the compression specimens, there did not appear to be any consistent relationships for the four-point bend specimens when comparing $c$ through the specimens with the bend strength, bend modulus and density. Although positive correlations were found in five situations, no significant trends were found across the different cements and mixing conditions investigated (Table 5). When the experimentally calculated values of $c$ were compared to the theoretically calculated values Eq. (3), it was evident that the values were distinctly different (Table 3).

The lack of agreement may have been due to the fact that $c$ was a function of the material alone, whereas the bend modulus was a function of both the material and specimen geometry. To eliminate the effect of the specimen dimensions on the bend modulus value, a shape factor was applied. The shape factor, $\varnothing$, was determined experimentally by testing specimens in four-point bend, as described previously Eq. (4):

$\phi=\frac{F_{F}}{F_{E}}$ 
Where $F_{F}=$ load at fracture $(\mathrm{N}) ; F_{E}=$ load at elastic limit $(\mathrm{N})$.

The heterogeneous nature of acrylic bone cement made it an unsuitable material to determine a shape factor as the presence of pores and/or unmixed powder could not be wholly taken in account. Instead, four-point bend specimens were created from general purpose acrylic sheet (Perspex ${ }^{\circledR}$ ). Perspex ${ }^{\circledR}$ was chosen as the main constituent of fully polymerised bone cement is acrylic and Perspex ${ }^{\circledR}$ sheet is unlikely to contain pores or in homogeneities within the bulk polymer. Three Perspex ${ }^{\circledR}$ specimens were tested and an average shape factor of $\varnothing=2.42 \pm 0.09$ was determined. This shape factor was used to calculate a new theoretical value of $c$ for each bone cement specimen using a modified version of Eq. (3):

$$
c=\sqrt{\frac{E_{Y} \times \phi}{\rho}}
$$

The average theoretical values of $c$ using Eq. (5) can be found in Table 3, percentage differences in the theoretically calculated $c$ values compared to the average determined experimentally. Final $c$ values for the acrylic bone cement specimens are also shown (Table 3).

\section{Discussion}

The variation in $c$ agrees with the general patterns observed in previous studies [15, 20]. This variation can be split into three stages: (1) initial plateau where there was little variation in $c$; (2) sharp increase when $c$ increased by $700-1100 \mathrm{~ms}^{-1}$; (3) $c$ levelling off into another plateau as the cement had fully hardened and there was no significant change in cement structure and therefore no change to $c$. Similar trends in variations of $c$ have been reported during cure monitoring of thermosetting resin consisting of polyester and styrene [22, 23] and epoxy resins [24].

The initial plateau can be attributed to an induction period caused by the presence of the inhibitor, hydroquinone. Polymerisation will not begin until all the inhibitor has been consumed 
[21ㄹ], leading to the initial plateau seen in the value of $c$.

The initial plateau or induction period was found to be longer for the acrylic bone cements prepared under atmospheric condition due to the presence of oxygen during atmospheric mixing. He et al. [13] established that oxygen molecules are known radical scavengers, which will join the inhibitor in stealing free radical molecules, causing the induction period to increase in duration.

The second stage involved a large rise in $c$ occurring rapidly over a period of 2-5 min, which corresponded with an increase in cement viscosity and inhibited the movement of growing polymer chains; allowing the sound pulses to travel faster, leading to the increase in $c$ through the mass. Similar trends have been reported during the monitoring of the setting/curing reactions of other systems; whereby a more organised, closely packed microstructure rather than consisting of particles in a solution [15, 20, 22, 23, 24]. Carlson et al. [18] did not report a similar finding when monitoring a calcium sulphate based bone cement. They found that as $c$ increased, the density actually decreased, which was attributed to the emerging crystalline microstructure of the cement, thereby propagating the sound waves faster rather than the closer packing of the molecules.

The final phase began when the rate of increase of $c$ had dropped. This was because the number of free monomer molecules left in the cement had dropped to a level that made the rate achieved under the Trommsdorff effect unsustainable [25]. The rate of chain growth decreased, leading to smaller changes in $c$ before the reaction had effectively terminated and $c$ levelled off to a plateau. Comparison with the limited literature available on ultrasonic monitoring of bone cement shows that the final values of $c$ obtained are in agreement with those reported previously [15, 20]. This is further confirmation that the test set up and equipment used in this current study was 
acceptable and can be compared to literature reliably.

In this study, both-the Palacos ${ }^{\circledR}$ R (p-values $<0.001$ ), SmartSet ${ }^{\circledR} H V$ (p-values $<0.001$ ) and Simplex $\mathrm{P}{ }^{\circledR}$ bone cements demonstrated average final $c$ values for the vacuum mixed cements, which were higher than those of the atmospherically mixed cement. The higher density for the cement prepared under vacuum led to a reduction in porosity content, which allowed for faster propagation of the sound waves through the hardened cement. Image analysis of cement sections showed that the porosity content was $2-4 \%$ for the cements prepared under vacuum, in comparison to $5-8 \%$ for the same cement composition mixed under atmospheric conditions. It was viewed that the presence of pores within the cement would result in sound waves having to propagate through small air pockets-of air, thereby slowing its overall travel through the cement mass.

After the final value of $c$ was found, it was possible to calculate the time to reach $75 \%$ and $95 \%$ of this value, and therefore determine the time parameter known as the cure duration [15, 20]. In this current study there was a greater agreement (Table 1) was observed when the time at $75 \%$ of the final value of $c$ was used to define the setting time as calculated using the temperature monitoring method [2], which was in agreement with previous studies [15].

The time of maximum temperature during polymerisation has been shown to indicate the end of the reaction $[16,17]$. In an effort to determine if this variable can be denoted using UT, a comparison was made between the time of maximum temperature and the time at $95 \%$ of final $c$. This time was chosen since it was used to indicate the end of cure duration. No agreement existed between the time of maximum temperature as defined by ISO5833:2002 and the time at 95\% of final c (Table 1). Whereas the temperature monitoring method only measured the temperature increase caused by the exothermic chain propagation; other techniques have been 
used to determine the end of reaction by monitoring the breakdown of the carbon double bond during chain propagation [16, 17], UT examines the overall microstructure of the cement. Although chain propagation will have ended at the time of maximum temperature, there will still be changes in the cement microstructure as termination takes place through two incomplete chain ends meeting or through electron transfer. This will lead to a change in $c$, even though other methods may suggest that the reaction is over.

Using both the cure time and the setting time, it was possible to investigate the effect that vacuum mixing has on the polymerisation reaction. Vacuum mixing decreased the setting time for all cements investigated (Table 1), although this reduction was not significant (p-values = 0.502, 0.543 and 0.068 for Palacos ${ }^{\circledR}$ R, SmartSet ${ }^{\circledR}$ HV and Simplex ${ }^{\circledR}$ P, respectively). This finding was in agreement with the trends previously reported in the majority of literature $[1,10$, 13]. For both mixing conditions, the Simplex ${ }^{\circledR}$ P bone cement exhibited longer setting times than the other two cements tested due to a longer induction period during which time there is no increase in $c$. After this initial period, the variation in $c$ was comparable to the other two bone cements and the large increase of the second phase actually occurred over a shorter period of time than for the Palacos ${ }^{\circledR}$ R and SmartSet ${ }^{\circledR}$ HV bone cements. To explain this observation it is necessary to consider the bone cement composition. Simplex ${ }^{\circledR}$ P bone cement has a greater amount of BPO (0.51g) when compared to Palacos® R bone cement $(0.3 \mathrm{~g})$ and the SmartSet ${ }^{\circledR}$ HV bone cement $(0.4 \mathrm{~g})$. Assuming that all of this BPO is converted into benzoyl radicals and these into active centres, there will be more points from which chains can grow and theoretically, polymerisation should therefore take place more rapidly.

The degree of monomer conversion, which is indicative of the extent of polymerisation was calculated using Differential Scanning Calorimetry [8] and the subsequent values recorded were 
within the previously range quoted for acrylic bone cement $[4,7]$. The Palacos ${ }^{\circledR} R$ and SmartSet ${ }^{\circledR}$ HV and Simplex $P{ }^{\circledR}$ bone cements when mixed under atmospheric conditions recorded a monomer conversion of $95.4 \pm 0.5 \%, 95.6 \pm 0.8 \%$, and $96.9 \pm 1.8 \%$ when mixed under atmospheric conditions. Applying vacuum to the mixing technique increased the degree of monomer conversion to $98.4 \pm 0.3 \%, 97.5 \pm 0.2 \%$, and $98.4 \pm 0.7 \%$, respectively.

Vacuum mixing increased the density and mechanical properties (Table 2 and Table 3), which supports the earlier argument that the increase in $c$ was caused by the change in density of the cement as it polymerised. It has been reported widely that acoustic properties can be used to determine mechanical properties for a wider range of materials including alumina ceramics [26] and trabecular bone [27]. A potential strong relationship between $c$ values, density and compressive strength of acrylic bone cement has been previously reported [15]. In this study, there were no significant correlations between the final velocity of sound and either the compressive strength or final density of the cement (Table 4). The only significant correlations existed between the cement density and compressive strength for both the Palacos ${ }^{\circledR}$ R and the SmartSet ${ }^{\circledR}$ HV bone cements mixed under vacuum and the Simplex ${ }^{\circledR}$ P bone cement mixed under atmospheric conditions. Examining the mechanical data for the four-point bend specimens, there were five cases out of 18 correlation analyses where a significant correlation was observed (Table 5). Unfortunately since no trends existed across all bone cements and mixing conditions it was difficult to determine with certainty that UT can be used to predicate the mechanical properties of polymerised bone cement.

Although the results are different to those found reported previously [15], there were distinctions between the two studies. Unlike the previous study [15], the ultrasonic properties of each compression specimen was not determined on an individual basis, rather the specimens were 
produced from each block of cured cement following the ultrasonic monitoring tests. The ultrasonic pulse did not pass through the whole block during testing so to use the value obtained for the block to represent all four specimens created required a broad assumption of homogeneity of mix. Kurdy et al. [28] used radiographic imaging to demonstrate that bone cement mix quality (pores and unmixed powder) can vary greatly, therefore the assumption of homogeneity within specimens is not accurate, possibly providing an explanation to the poor correlations obtained.

Poor correlations were also found when conducting correlation analyses between the final $c$ values and cement density, bend strength and bend modulus of the four-point bend specimens. Cement homogeneity was not an issue in this instance since the ultrasonic measurement was taken at the fracture site. However, pores within the cement microstructure could have had an influence on the correlation analysis. Pores act as potential stress raisers since they reduce the surface area of cement over which the load acts. This will lower the load that the specimen can withstand. The pore may not have the same effect on the $c$ value at the point of fracture. It is postulated this could be for one of two reasons: (1) the area of the pore will be small in comparison to the area of the transducer or (2) the 'critical pore' may be involved in the fracture process and therefore unavailable for subsequent scanning and therefore will not have a noticeable effect on the speed of the pulse through the specimen. For this reason significant correlations between the ultrasonic and final mechanical properties could not be found consistently.

The theoretical $c$ values obtained from the four-point bend specimens using Eq. (3) are not in agreement with the experimentally determined values of $c$ (Table 3). Recalculation of the theoretical $c$ values, taking into account this shape factor (Eq. 5), it was found that there was a 
much closer agreement with the experimentally determined $c$ values (Table 3). Although there is still a level of error present (9.26-13.89\%), which may be attributed to inhomogeneous material properties or the fact that the shape factor was calculated using pure PMMA, whereas the cements contain a proportion of other substances.

The theoretical values for $c$ were determined using the respective bend modulus value and density. The density used was the apparent density calculated using Archimedes' principle. Although there is a degree of error using this method, a high level of consistency was observed for the density values within a particular cement batch. It has been stated that mechanical testing is not the most accurate method of determining the modulus of a material since there is the possibility of material creep and deflection of the testing machine [201]. If there were errors in the recorded cement density or modulus it would affect the calculated theoretical value for $c$ and may also help to explain the error between theoretical and experimental values.

Therefore considering all the results; the pulse-echo ultrasonic test method could be used as an effective and reliable method for following the full polymerisation reaction of acrylic bone cement in real-time and then determining the setting properties within a surgical theatre environment. However the application of similar technology for predicting the final mechanical properties of acrylic bone cement on a reliable and consistent basis may prove difficult. Further studies are now underway in an effort to integrate such UT within an automated bone cement mixing system, whereby the polymerisation reaction can be monitored in real-time and the bone cement delivered at the correct time irrespective of cement type, mixing condition and environmental conditions.

\section{Conclusions}

A critical examination of the relationship between polymerisation reaction, mechanical 
properties and acoustic properties for three different types of acrylic bone cement when mixed under atmospheric and vacuum mixing conditions was conducted using the pulse-echo ultrasonic technique. The main conclusion of the study was for a given cement, the polymerisation reaction and principal setting characteristics can be accurately determined in real-time irrespective of the mixing technique adopted. However using the final acoustic properties of acrylic bone cement to predict its mechanical properties may prove problematic and less straightforward as inhomogeneities within the cement microstructure and specimen geometry may have a significant influence.

\section{References}

[1] N.J. Dunne, J.F. Orr, Curing characteristics of acrylic bone cement, J. Mater. Sci: Mater. Med. 13 (2002) 17-22.

[2] ISO 5388. (International Organisation for Standards, Geneva, 2002).

[3] R. Eveleigh R, Temperature and its effect on bone cement, Br. J. Perioperative Nursing 11 (4) (2001) 164-168.

[4] K.D. Kühn, W. Ege, U. Gopp, Acrylic bone cements: composition and properties, Orthop. Clin. .N Am. 36 (2005) 17-28.

[5] P.R. Meyer, E.P. Lautenschlager, B.K Moore, On the setting properties of acrylic bone cement, J. Bone Joint Surg. 55-A (1) (1973) 149-156.

[6] S.S. Haas, G.M. Brauer, G. Dickson, A characterisation of polymethylmethacrylate bone cement, J. Bone Joint Surg. 57-A (3) (1975) 380-391.

[7] C.I. Vallo, P.E. Montemertini, T.R. Cuadrado, Effect of residual monomer content on 
some properties of a poly(methyl methacrylate)-based bone cement, J. Appl. Poly. Sci. 69 (1998) 1367-1383.

[8] C.I. Vallo, Theoretical prediction and experimental determination of the effect of mold characteristics on temperature and monomer conversion fraction profiles during polymerisation of a PMMA-based bone cement, J. Biomed. Mater. Res. Part B 63 (2002) 627-642.

[9] W. Jiranek, Thermal manipulation of bone cement, Orthopaedics 28 (8) (2005) s863866.

[10] D. Hansen D, J.S. Jensen, Prechilling and vacuum mixing not suitable for all bone cements, J. Arthroplasty 5 (1990) 287-290.

[11] N.M.G. Kurdy, J.R. Hodgkinson, R. Haynes R, Acrylic bone cement-Influence of mixer design and unmixed powder, J. Arthroplasty 11 (7) (1996) 813-819.

[12] L. Lidgren, B. Bodelind, J. Möller, Bone cement improved by vacuum mixing and chilling, Acta. Orthop. 57 (1987) 27-32.

[13] S. He, C. Scott, P. Higham, Mixing of acrylic bone cement: effect of oxygen on setting properties, Biomaterials 24 (2003) 5045-5048.

[14] S. He, C. Scott, M. De Luise, B. Edwards, P. Higham, Effect of choice of surgical glove on dough time measurements of acrylic bone cements, Biomaterials 24 (2) (2002) 2235-237.

[15] N.J. Dunne, Y. Xu, J. Makem, J. Orr, Ultrasonic characterisation of the mechanical properties and polymerisation reaction of acrylic-based bone cements, Proc. IMechE H. 221 (2006) 251-261.

[16] C.P Hagan, J.F. Orr, C.A. Mitchell, N.J. Dunne, Real time monitoring of the 
polymerisation of PMMA bone cement using Raman Spectroscopy, J. Mat. Sci: Mat. Med. 20 (2009) 2427-2431.

[17] I. Rehman, E.J. Harper, W. Bonfield, In-situ analysis of the degree of polymerisation of bone cement using FT-Raman spectroscopy, Biomaterials 17 (16) (1996) 1615-1619.

[18] A. Briscoe, A. New, Polymerisation stress modelling in acrylic bone cement, J. Biomech. $43(2010) 978-983$.

[189] J. Carlson, M. Nilsson, E. Fernandez, J.A. Planell. An ultrasonic pulse-echo technique for monitoring the setting of $\mathrm{CaSO}_{4}$ based bone cement, Biomaterials 24 (2003) 71-77.

[1920] A.M. Viano, J.A. Auwarter, J.Y. Rho, B.K. Hoffmeister, Ultrasonic characterisation of the curing process of hydroxyapatite modified bone cement. J. Biomed. Mater. Res. Part B 56 (4) (2001) 593-599.

[201] M. Ashby, H. Shercliff, D. Cebon, Materials: Engineering, science, processing and design, second ed., Elsevier Limited, Oxford 2006.

[212] F. Lionetto, A. Tarzia, A. Maffezzoli, Air coupled ultrasound for monitoring curing of thermosetting matrices. IEEE Transactions on Ultrasonics, Ferroelectrics and Frequency Control 54 (7) (2007) 1437-1444.

[23] F. Lionetto, A. Maffezzoli, Polymer characterization by ultrasonic wave propagation, Adv. Poly. Techn. 27 (2) (2008) 63-73.

[2z4] R.E. Challis, M.E. Unwin, D.L. Chadwick, R.J. Freemantle, I.K. Partridge, D.J. Dare, P.I. Karkanas, Following network formation in an epoxy/amine system by ultrasound, dielectric, and 
nuclear magnetic resonance measurements: A comparative study, J. Appl. Poly. Sci. 88 (2003) $1665-1675$.

[235] G. Odian, Principles of Polymerisation, fourth ed., John Wiley and Sons, New Jersey 2004.

[246] L.S. Chang, T.H. Chuang, W.J. Wei, Characterization of alumina ceramics by ultrasonic testing, Materials Characterisation 45 (2000) 221-226.

[257] J.P.W. Van Den Bergh, G.H. Van Lenthe, A.R.M.M. Hermus, F.H.M. Corstens, A.G.H. Smals, R. Huiskes, Speed of sound reflects Young's modulus as assessed by microstructural finite element analysis, Bone 26 (5) (2000) 519-524.

[26ㅈ] N.M.G. Kurdy, J.P. Hodgkinson, R. Haynes, Acrylic bone cement: Influence of mixer design and unmixed powder, J. Arthroplasty 11 (7) (1996) 813-819. 